\title{
The Prospect and Introspection of Technology Educational Innovation
}

\author{
Zhixing Shi ${ }^{*}$, Junjie Ma $^{2}$ \\ ${ }^{1}$ College of International Education, Capital Normal University, Beijing 100048, China \\ ${ }^{2}$ Moray House School of Education and Sport, The University of Edinburgh, Edinburgh EH8 9YL, United Kingdom \\ *Corresponding author: Zhixing Shi, 2926773386@qq.com
}

\begin{abstract}
The development and popularization of online classroom is an inevitable trend given the tremendous progress of science and technology and the advent of $5 \mathrm{G}$ information era. In this special period, if possible, most of the offline classes are converted to online classes, using tablets or computers for online classes. Online classes are divided into video class and live class, which provides convenience and security. However, online classroom is limited by factors, such as low efficiency and the fact thar teachers can't supervise students' actual situation. Thus, the gradual popularization of virtual reality (VR) classroom has slowly improved the immersive classroom experience of students and teachers. This paper attempts to analyze the problems existing in students' online classroom learning in the special period, and whether the interaction between teachers and students can improve the classroom efficiency. VR classroom provides more benefits, and at the same time, this new teaching mode comes with improved basic equipment required by VR classroom. Traditionally, library is the obvious choice for students to look for additional information and references, which is however not a convenient option at present. The emergence of mobile online library has undoubtedly made learning easier. The research may help to study the influence of the development of science and technology on the real education mode.
\end{abstract}

Keywords: Virtual reality; Online classroom; Technology; Immersive; Mobile library

Publication date: August 2021; Online publication: August 30, 2021

\section{Introduction}

Technology has developed with remarkably rapid pace in recent years. The continuous innovation and progress of science and technology has benefited mankind in every area. The rapid development of science and technology has provided an unprecedented driving force for economic and social development. A new round of scientific and technological revolution and industrial change around the world have accelerated the evolution. The world economic pattern and industrial form are facing the challenge of reshuffle. According to $\mathrm{Li}$ and $\mathrm{Gu}$, the increasing investment in high-tech talents with innovative ability is the key point for countries to control the changes in the information age, and education is an essential process to produce the "high-end talents." [1] Conversely, under the special circumstance of the coronavirus disease 2019 (COVID-19), the education industry bears the brunt of the pandemic repercussions, and students were required to stay at home and continue to have the lessons. Thus, online classroom has suddenly become very crucial and increasingly prominent at this timepoint, and high technology can be applied to online classroom. However, there are many issues in online classroom. Virtual reality (VR) classroom could replace the classical online classroom, but it needs more device. The existence of $5 \mathrm{G}$ provide higher network speed and steady network environment. Subsequently, with the higher network speed and more advanced technology, students can look for the information such as using the dictionary and finding the academic information without having to go to the physical library. 


\section{Online classroom}

\subsection{Teachers cannot use online teaching software flexibly}

From Guo's point of view, teachers' understanding of online teaching, especially in the aspects of their perspectives toward online teaching, ways to integrate into online teaching, as well as ways to make online teaching different from the traditional face-to-face classroom teaching, has not been comprehensively studied [2]. Many teachers cannot adapt to the online teaching mode well, and they have troubles familiarizing themselves with the use of these software. Particularly, the older teachers are very unskilled in the use of computer equipment, and they are often unable to solve the minor glitches in the software; as a result, the lesson cannot be carried out efficiently. The traditional mode of teaching requires that teachers write teaching content on the blackboard with chalk. Once online teaching is to replace the older mode, a great deal of teachers may have difficulties using the software, which will affect the classroom efficiency.

\subsection{Cultivating students' consciousness of independence}

When students are taught online, there is a great probability that they will not listen carefully. The most significant difference between online classroom and offline classroom is that teachers cannot supervise students in online class. Students are forbidden to bring mobile phones into the school, so no students will play with electronic devices in the physical class. However, online teaching students will not be supervised by teachers, they can wander, chat, even play mobile phones or computer games on the other side of the screen. Online classroom software should make use of technology, so that teachers can observe students' computer screen in real time, so as to pay attention to whether students listen to the class carefully. Attention detection system should be set up in the computer camera of students' end to detect whether students are paying attention in class. All these technologies are achievable at this stage.

\section{Application of high technology}

\subsection{VR classroom}

Nowadays, with the development of science and technology, the traditional classroom teaching mode has become obsolete and is unable to meet the needs of students to acquire knowledge. To a certain extent, it limits students' creativity as it only promotes their horizontal thinking. Wang also claimed that students' learning mode is roughly the same, which limits their self-initiative ${ }^{[3]}$. According to Heim, VR technology means that "with the support of computer software, hardware and various sensors, a realistic, threedimensional environment with certain perception ability of seeing, listening, touching, and smelling can be generated." [4]

VR technology is now gradually applied to various fields, such as medical education and simulation of surgery, greatly reducing costs and risks. The game industry uses VR technology to make players feel immersive and greatly improve the game experience. Undeniably, the biggest feature of VR technology is that it provides immersive experience to user. In reality, it can be used in teaching and education. In the special period, students who cannot go back to school can learn in an environment similar to the real classroom by using VR technology. Since it is almost the same as a real classroom, the students' efficiency in class will be very close to that of a real classroom, which is much better than that of an online classroom. Nevertheless, the use of VR technology requires a lot of costly electronic equipment, such as VR glasses, high-performance computer, and image generation system. As it has not been popularized, the cost of VR technology is relatively expensive. At present, it is not very reliable to use VR technology for classroom teaching. Of course, the application of VR technology in online teaching mode is an inevitable trend of development. 


\subsection{Artificial intelligence (AI) teaching}

The combination of AI and education has become the common aspiration of all countries in the world. On October 12, 2016, The Machine Learning and Artificial Intelligence Sub-committee of U.S. released "Preparing for the Future of Artificial Intelligence" and "National Artificial Intelligence R \& D Strategic Plan," which incorporated AI application into the field of education ${ }^{[5]}$.

At present, AI technology is gradually integrated into education. The traditional education remains the mainstream approach currently. Even VR technology and online classroom teaching are introduced for application in teaching, the lessons will still be conducted by real teachers. AI teaching has made a substantial breakthrough in the teaching, the management of students and the different learning methods of different students. AI has carried out deep learning for this purpose, and simulated the teaching methods of real teachers.

According to $\mathrm{Wu}$ and Ping's summarization, the realization of education management intellectualization by AI is mainly reflected in four aspects: (i) At the teacher level, the education AI system can accurately draw teachers' portraits and provide teachers with targeted training programs and teaching resources to help teachers' career development. Meanwhile, through timely data statistics and information feedback, it can help teachers improve teaching strategies, adjust teaching content, and effectively guide students to learn. Moreover, the educational AI system also plays a great role in student management. Its functions, such as automatic submission and correction of homework, intelligent question answering and paper correction, not only improve teachers' work efficiency, but also accurately demonstrate students' knowledge map for teachers, so that teachers can clearly understand students' knowledge gap. (ii) At the school level, it is mainly manifested in the intelligent management of campus security, teaching resources allocation, teacher management and learning supervision. (iii) At the family level, it mainly meets the needs of parents to understand students' learning situation, popularize family education knowledge, facilitate family-school cooperation and provide guidance to students, so as to solve the fundamental issues of family education inadequacy. (iv) At the level of education managers, it mainly provides reference for education managers in the aspects of intelligent development strategy and education policy ${ }^{[6]}$.

For the future development of AI teaching, we need to determine the service role of AI, actively change the role of teachers and students, develop AI school, improve the curriculum, and optimize the national investment in AI education since a lot of funds and support are required.

\subsection{Mobile Library}

Mobile devices which include mobile phones, tablet computers and pad are indispensable devices for mobile library services, and play an important role in mobile acquisition, processing, and interaction of library services. Mobile devices not only broaden the service mode of traditional libraries, but also strengthen the functions and roles of libraries and librarians in mobile learning and mobile education. Some scholars at home and abroad have discussed this from different angles. In the aspect of mobile learning, Shi and Xia argued that from the perspective of Barnhart et al., mobile devices will change the way and place of teaching. They suggest that librarians should learn to use mobile devices in the mobile learning environment to provide better reference services for users. Mobile devices usher in a revolutionary stage of application in higher education. This paper discusses the potential of promoting personalized learning. For example, users can get the guidance and help of librarians through mobile devices when they need to, or use mobile devices to generate digital learning content, rather than just from the library collection; Squire asserts that mobile devices will maximize learning capacity which is greatly limited in the form of traditional learning (such as classrooms). In the mobile education aspect, Murray discusses the significance of Library Mobile Education in distance education, and thinks that it can provide help for learners who do not have libraries or librarians in their own areas. The application of mobile devices in library user learning 
and user education will be more popular and important, and presents a new solution to solve the problem of shortage of domestic teaching resources, and then help to improve the quality of teaching. These are the effects of mobile library on the application of science and technology in education ${ }^{[7]}$.

\section{Conclusion}

Despite the drawbacks, teachers are encouraged to learn the technology for innovating educational model in contemporary classroom teaching. In conclusion, this paper analyzes the differences between traditional teaching and teaching mode innovated by science and technology, as well as the effect of hybrid VR and online teaching. These features will become a new trend of teaching mode, and teachers also need to try to adopt a mixture of these models according to different situations.

\section{Disclosure statement}

The authors declare that there is no conflict of interest.

\section{Author contributions}

Z.S. conceived the idea of this research and was responsible for the main compilation. J.M. organized literatures and supervised the research.

\section{References}

[1] Li AX, Gu XQ, 2018, Black-tech for Learning Technology: Will Artificial Intelligence Bring Disruptive Innovation to Education? Modern Educational Technology, 29(05): 12-8.

[2] Guo YJ, 2020, Yiqing Fangkong Shiqi de Wangluo Jiaoxue: Wenti, Duice yu Fansi [Online Teaching in the Period of Epidemic Prevention and Control: Problems, Countermeasures and Reflections]. Dangdai Waiyu Yanjiu [Contemporary Foreign Language Studies], 1: 10-1.

[3] Wang M, 2013, Design and Implementation of Teaching System Based on VR Display and Communication. Shanghai Jiao Tong University.

[4] Heim M, 2000, From Interface to Cyberspace: Metaphysics of Virtual Reality. Shanghai Science and Technology Education Press, Shanghai.

[5] Preparing for the Future of Artificial Intelligence, Kexue Jishu Lishihui Jishu Weiyuanhui Zhuxi Bangongting [Executive Office of the President National Science and Technology Council Committee on Technology]. https://obamawhitehouse.archives.gov/blog/2016/05/03/preparing-future-artificialintelligence (accessed July 10, 2021).

[6] Wu JY, Ping LD, 2008, Rengong Zhineng zai Xiandai Yuancheng Jiaoyu zhong de Yingyong [Application of Artificial Intelligence in Modern Distance Education]. Zhonnguo Yuancheng Jiaoyu [Distance Education in China], 12: 66-9.

[7] Shi QH, Xia QL, 2013, Yidong Tushuguan Yanjiu de Huigu yu Zhanwang [Review and Prospect of Mobile Library Research]. Zhongguo Tushuguan Xuebo [Journal of Library Science in China], 40(02): $83-4$. 